\title{
A influencia das linguas dominantes no desenvolvemento de políticas de linguaxe non-sexista en linguas subordinadas: análise do caso do galés
}

\author{
Robert Neal Baxter \\ Universidade de Vigo
}

\begin{abstract}
Resumo:
Partindo dunha análise do caso concreto das propostas para a elaboración dunha política oficial de linguaxe non-sexista para o galés, este artigo, por unha parte, explora como a condición de lingua subordinada inflúe nas decisións estratéxicas perante a planificación non-androcéntrica e, por outra parte, indaga nas posíbeis implicacións que supón a translación mecánica de estratexias elaboradas previamente para a correspondente lingua dominante, sobre todo ao existiren diferenzas substanciais entre as dúas linguas en cuestión (o galés e o inglés) no xeito de reflectiren o xénero 'biolóxico' dos referentes humanos a través das súas respectivas gramáticas. Asemade, o artigo contrasta as posíbeis repercusións de determinadas estratexias, denominadas 'neutralización', 'explicitación' e 'transgresión radical'. Aínda recoñecendo as diferenzas que existen entre as diversas linguas subordinadas en función das súas respectivas situacións e marcos de desenvolvemento, o artigo conclúe que as reformas non-androcéntricas non son incompatíbeis coa preservación de linguas ameazadas, de forma que poden -e deben- pasar a formar parte integral dos esforzos xerais de planificación lingüística.
\end{abstract}

\section{Palabras chave:}

Lingua subordinada, política lingüística, linguaxe non-discriminatoria, linguaxe androcéntrica.

\begin{abstract}
:
Based on an analysis of the case of the proposals for the official non-sexist language policy for Welsh, on the one hand, this paper explores to what extent strategic decisions regarding the implementation of non-androcentric are affected by the subordinated status of such languages, whilst at the same time discussing the possible implications of mechanically importing strategies previously drawn up for the dominant language, especially in cases where there is a significant discrepancy between the way either language (in this case Welsh and English) linguistically encode the 'biological' gender of human referents. The article goes on to compare the possible repercussions caused by the application of three the main of strategies, labelled 'neutralisation', 'explicitation' and 'radical/disruptive'. Whilst recognising that not all subordinated languages share the same characteristics and framework, the paper concludes that non-androcentric language reform ventures are not incompatible with the conservation of endangered languages, making it not only possible but necessary to integrate them into the wider language planning framework.
\end{abstract}

\section{Key words:}

Subordinated language, language policy, non-discriminatory language, androcentric language. 


\section{Introdución}

No language -not even Scotland's oldest- is safe from the modern-day curse of political correctness. Gaelic is being purged of a host of words that are age and gender specific in an effort to make it acceptable to sensitive 21 st-century ears (MacLeod 2003).

Como ben indica esta citación introdutoria, a xa de por si espiñenta cuestión da linguaxe 'politicamente correcta' (véxase máis adiante as consideracións sobre este e outros termos) fica complicada aínda máis cando se trata da súa aplicación ás linguas subordinadas, debido ao rango que se lles asigna como vehículo privilexiado dos valores 'tradicionais' que teñen de ser protexidas de influencias exóxenas, incluída calquera imposición -real ou percibida- desde as súas respectivas linguas dominantes.

Deixando para un lado de momento as consideracións ideolóxicas que subxacen ao uso dunha determinada terminoloxía referida á cuestión da linguaxe 'politicamente correcta', o que no fondo revela esta citación é que existe a probabilidade de se percibiren políticas de intervención lingüística destinadas a promoveren unha linguaxe non-discriminatoria e, máis especificamente, non-androcéntrica, como unha inxerencia externa que ameaza a autenticidade da lingua 'natural' que se vén transmitindo de xeración en xeración de xeito espontáneo. No caso das linguas subordinadas, entendidas como o bastión da cultura tradicional, tales tentativas de intervención lingüística planificada percíbense para alén de máis como unha ameaza, non só para a lingua en si, senón tamén, por extensión, para a cultura tradicional que esta vén representando simbolicamente. Así, calquera proxecto de planificación do corpus lingüístico que tiver como propósito reformar directamente a linguaxe modificando os seus usos para reflectiren e/ou fomentaren a normalización social de grupos até agora marxinados (neste caso, as mulleres) percíbese frecuentemente como enfrontado con outras políticas lingüísticas destinadas a planificaren o status ('normalización') e a codificación ('normativización') destas mesmas linguas co propósito de ampliar e incrementar o seu uso na sociedade en xeral.

Noutras palabras, até as/os propias/os axentes implicadas/os directamente na planificación lingüística tradicional das linguas subordinadas poden considerar a planificación e promoción dunha linguaxe non-androcéntrica non só como tarefas secundarias, senón como un factor que mesmo pode restar pulo e credibilidade á tarefa prioritaria de 'salvar' a lingua.

Fronte a estas percepcións, o presente artigo argumenta, polo contrario, que estas dúas vertentes da planificación lingüística -a planificación non-discriminatoria por unha banda e a planificación do status e do corpus xeral por outra-non teñen porque ser incompatíbeis, senón que, hoxe por hoxe, a planificación de usos nondiscriminatorios da lingua forma-ou debería formar-unha parte integral das políticas lingüísticas de planificación de corpus globais, pois unha lingua que non se adapta 
ás necesidades das falantes actuais está abocada á musealización, por moito que se salvagardar a súa "pureza tradicional". De feito, a maior proba da vitalidade dunha lingua é a súa capacidade de mudar continuamente para se adaptar ás necesidades de cada nova xeración de falantes. Así, a pregunta que cabe facerse ao se emprenderen reformas e políticas lingüísticas aplicadas a unha lingua subordinada non ten tanto que ver con a querer preservar sen máis, tal como está ou estaba nun determinado momento cos seus correspondentes factores sociolóxicos, senón que tipo de lingua se quere perpetuar e para que usuarias/os na actualidade. Dito doutro xeito, ao deseñar e levar a cabo unha estratexia de planificación lingüística global e coherente cómpre tomar en conta non só o obxecto (a lingua), senón tamén o suxeito (as/os falantes, tanto reais como potenciais).

Este artigo toma como caso de estudo o galés, unha lingua subordinada dentro do marco xeopolítico do Reino Unido suxeita á influencia do inglés como lingua dominante. Indaga nas razóns obxectivas que inflúen na adopción de medidas de reforma lingüística concretas para chegar a unha lingua non-discriminatoria, onde o que subxace ás decisións tomadas non son tanto as necesidades e capacidades internas da lingua en cuestión, senón as políticas aplicadas na correspondente lingua dominante, como reflexo claro da subsidiariedade desta.

O caso galés é particularmente interesante por dúas razóns principais, intimamente ligadas entre si:

1. No nivel interno, demostra clarisimamente que os esforzos para crear e impulsar un uso non-discriminatorio dunha lingua subordinada non lle restan necesariamente importancia á tarefa xeral da normalización desta.

2. No nivel externo, pon en destaque, asemade, a situación subordinada da lingua a respecto da lingua dominante, ao se aplicaren ao galés reformas lingüísticas homologábeis a aquelas aplicadas á súa correspondente lingua dominante, o inglés, a pesar das grandes diferenzas existentes no relativo á codificación gramatical do xénero.

\section{Lingua e xénero}

É hoxe un feito indiscutíbel que existe unha relación entre a linguaxe e o seu uso por un lado, como produto e construto da interrelación social ao longo do tempo e dentro de determinados parámetros socioculturais, e o xeito en que veñen representados simbolicamente os respectivos papeis que se reservan aos homes e ás mulleres. Noutras palabras, a linguaxe será na súa expresión (case) inevitabelmente sempre sexista en sociedades estruturadas de xeito sexista, entendido isto como a asignación asimétrica de papeis sociais segundo o xénero ‘biolóxico’ de cada individuo. 
De feito, en canto se refire aos seres humanos, esta íntima imbricación entre o binomio xénero 'biolóxico' (home/muller) e a asignación de xénero gramatical (masculino/ feminino) nas linguas que recorren a tales mecanismos sempre responde a un cerne semántico (Corbett 1991: 34), moi a pesar dos diferentes criterios secundarios ou aparentes de asignación (morfoloxía, fonoloxía etc.). Isto é, a natureza do xénero gramatical, lonxe de constituír unha categoría arbitraria propia do funcionamento interno dunha determinada lingua, está en estreita relación co xénero 'biolóxico' e coa asignación de papeis sociais como construto sociocultural.

Así pois, aínda rexeitando o determinismo lingüístico expresado de xeito máis categórico na hipótese de Sapir-Whorf, fica claro que o xeito en que as linguas plasman o xénero ‘biolóxico’ reflicte e tamén moldea as representacións que se fan dos ditames sociais correspondentes á asignación de papeis tal e como se perciben por parte das e dos falantes:

language both reflects and constructs women's status as Other as it defines women's position as inferior in relation to men. [...] if male and female identities are largely constructed and transmitted through language [...], then language change is obviously critical (Romaine 1999: 291).

One of the basic principles of feminism is that society has been constructed with a bias which favours males; one of the basic principles of feminists who are concerned with language is that this bias can be located in the language (Spender 1980: 14).

No entanto, o certo é que diferentes linguas -nos casos en que o fixeren-utilizan unha variedade de estratexias lingüísticas no momento de plasmaren as correspondencias co xénero ‘biolóxico’ (véxase Bußman / Hellinger 2001-2003). Sería lóxico pensar, pois, que as estratexias elaboradas co obxectivo de acadaren unha proposta de linguaxe non-sexista tamén variarían en función da tipoloxía de cada unha delas. A modo de ilustración, eis varios exemplos de como unha lingua pode marcar o xénero biolóxico como parte integral da súa gramática, non sendo necesariamente exclusivos entre si os diferentes procedementos:

pronomes persoais, p.e. terceira persoa singular e plural (galego: el/ela; eles/ elas); terceira persoa singular só (inglés: he/she; they); segunda persoa singular informal (euskera: duk/dun); primeira e segunda persoas do plural (español: nosotras/os; vosotras/os);

flexión verbal, p.e. árabe $f a^{c} a l a$ 'el fai'; $f a^{c}$ alat 'ela fai';

clasificación de substantivos marcados de diversos xeitos, p.e. concordancia cos determinantes e/ou a morfoloxía adxectival (galego: un bo profesor $\sim$ unha boa profesora); francés: un bon professeur ('un bo profesor') une bonne professeur ('unha boa profesora'); mutación inicial (bretón: ur c’helenner 
mat ('un bo profesor') ur gelennerez vat ('unha boa profesora'); elementos léxicos (inglés: a male teacher ('un profesor') a woman teacher ('unha profesora')

Mais, a pesar destas diferenzas gramaticais superficiais, xorde, a pouco que se investigar, un trazo común que une todos estes sistemas canto á expresión gramatical do xénero 'biolóxico': o uso xeneralizado do masculino como referencia básica por antonomasia (pseudoxenérico masculino) para se referir a todos os seres humanos ("the benchmark for all human beings", Pauwels 1998: 34). De se non corrixir, esta práctica leva ineludibelmente a unha representación lingüística asimétrica entre homes e mulleres, como por exemplo a non marcaxe das formas masculinas, entendidas como básicas e con rango de hipónimo, fronte a marcaxe das formas femininas derivadas das anteriores, entendidas como secundarias e con rango de hiperónimo, p.e. doutor > doutora, ou mesmo en esperanto patro ('pai') > patrino ('mai'). É dicir, a muller está representada na linguaxe como unha subespecie de ser humano, varón por defecto.

Con todo, non é o feito de as linguas expresaren o xénero 'biolóxico' como parte integral das súas gramáticas o que as torna necesariamente sexistas. Por exemplo, non é necesariamente sexista distinguir formalmente entre 'pai' e 'nai'. O que si resulta sexista, polo contrario, é a asimetría no seu funcionamento e nos seus usos reais, partindo e dependendo das expectativas e normas socialmente construídas no tocante aos papeis asignados a homes e mulleres na sociedade, o que leva a usos androcéntricos da linguaxe debido a que as linguas se desenvolven e se utilizan dentro dun entorno á súa vez androcéntrico: por exemplo, utilizar o masculino 'pai' como se fose xenérico para se referir tanto a pais como a nais.

Este artigo céntrase, pois, nas diferentes estratexias adoptadas co fin de reformar os usos lingüísticos dun xeito intencionadamente non-androcéntrico, analizando os factores endóxenos e esóxenos que motivan e condicionan a aplicación de determinadas estratexias en cada caso. Antes de máis, cómpre esclarecermos a terminoloxía usada, non exenta, neste caso tan polémico, de matices ideolóxicos importantes. Optaremos por utilizar o termo máis amplo 'linguaxe nondiscriminatoria', tal e como recollen os documentos oficiais no caso da lingua galesa ("non-discriminatory language") por ser máis neutral/positivo e máis global na súa aplicación do que o termo 'politicamente correcto', talvez máis coñecido, mais á súa vez tamén máis ambiguo, hoxe por hoxe moi desvalorizado e cunha carga altamente negativa, chegando mesmo o 'politicamente incorrecto' a representar unha postura radical e rompedora ${ }^{1}$.

1 Cameron (1995: 123-130) describe o xeito en que o termo 'politicamente correcto' mudou de sentido, até chegar a ter un valor marcadamente negativo. 


\section{Estratexias: transgresión radical, neutralización e explicitación}

Dentro do amplo espectro que presenta a planificación lingüística nondiscriminatoria, o presente traballo céntrase na cuestión máis concreta das tentativas e estratexias despregadas para acadaren unha lingua se non nonandrocéntrica, polo menos menos androcéntrica. Escóllese moi conscientemente o termo 'non-androcéntrico' (véxase Spender 1980: 14-16), para subliñar a natureza androcéntrica dos usos estabelecidos e para poder englobar unha serie de propostas estratéxicas con diferentes alicerces ideolóxicos que, aínda que non sexan sempre complementares entre si, si reúnen o criterio común de pretender rachar coa supremacía do masculino tal e como se ve reflectido na linguaxe. Nun extremo deste abano áchase unha serie de propostas máis conservadoras, con frecuencia baseadas en falsas premisas a respecto dos verdadeiros propósitos dunha intervención lingüística deste tipo: "El discurso feminista está muy claro: puesto que no es posible abolir las injusticias suprimiendo las diferencias sexuales [...], suprimamos las diferencias de género, empezando por el lenguaje" (Oroz s.d.: 1).

Son falsas crenzas como esta as que levan á idea -errónea ao noso ver- de que as tentativas de desandroxinizaren a lingua deben estar orientadas cara a estratexias tendentes a 'neutralizaren o xénero' ('gender-neutralisation', Pauwels 1998: 109-112), argumentando, por extensión, que calquera tentativa de reforma máis 'radical'-isto é, devolver ás mulleres un lugar nos usos lingüísticos a par cos homes- non sería menos que absurdo:

En español, en lugar de 'neutralizar' el lenguaje, se acude a veces al extremo opuesto, el de feminizarlo, lo que conduce a aberraciones como 'jueza' [...]. Lo terrible de estas ridículas palabras radica en que consiguen que un problema realmente importante parezca una tontería (Oroz s.d.: 2-3).

Por razóns similares, Cameron tamén critica a postura defendida por Doyle (1995), acusada de 'postura liberal' (“liberal approach", Cameron 1998: 158). Poderían ser cualificadas posturas como estas de 'non-sexistas' en canto que avogan pola neutralización das diferenzas de xénero nos usos lingüísticos. De aí, como se verá a continuación, que estratexias globalmente 'non-androcéntricas' no seu enfoque non teñen por que coincidir necesariamente con estratexias 'nonsexistas', entendidas estas últimas nos termos que se acaban de expor.

Existen, paralelamente coa neutralización, outras estratexias que teñen como obxectivo último reformaren os usos lingüísticos nun sentido non-androcéntrico. Competindo coas máis tímidas estratexias destinadas a mitigaren a distinción de xénero nos usos lingüísticos, verifícanse outros modelos máis 'radicais' sustentados en posicionamentos e orientados a fins radicalmente opostos: "disrupt 
the complacency with which dominant groups regard their own ways of using language as the only legitimate or intelligible ways of using it" (Cameron 1995: 162).

Lonxe de se tratar de estratexias non-sexistas, aquí do que se fala é de estratexias xinocéntricas en contraposición á dominación dos usos androcéntricos existentes. En vez de tornar a muller invisíbel a través da neutralización, o que se pretende é deliberadamente estrañar e provocar para romper coa compracencia de que goza o androcentrismo como discurso dominante, ou cando menos desenmascaralo, suscitando debate e o seu cuestionamento. Bo exemplo diso é a substitución dos pseudoxenéricos masculinos por pseudoxenéricos femininos, p.e. "Tengo dos hijas, un niño y una niña." (Moreno 2009).

Un exemplo moi próximo dunha estratexia 'radical' que rompe coas normas habituais da lingua escrita atópase no uso da arroba (@) en linguas como o galego. A resistencia con que se vén enfrontando a aplicación práctica de tales estratexias como recomendación integrada dentro das políticas de planificación non-sexista/anti-androcéntrica radica na necesidade de manter, custe o que custar, a 'naturalidade' da lingua:

non debemos abusar dos recursos cos que conta a lingua neste sentido [...] ou acabariamos empregando unha linguaxe antinatural e afastada da gramática [...] non se recomenda a alternativa, cada vez máis difundida, de usar o signo de arroba $<@>$ para neutralizar os masculinos sintéticos (Rodríguez Rodríguez 2003: 52, 56).

Voltaremos máis adiante sobre o peso preponderante que se atribúe a este criterio de 'naturalidade' no caso concreto do galés. $\mathrm{O}$ obxectivo primordial de estratexias 'transgresoras' non consiste, porén, en tentar facer encaixar as mulleres dentro da linguaxe androcéntrica preexistente do xeito máis inocuo posíbel mediante reformas que poden pasar desapercibidas por non cuestionaren as expectativas existentes. O que si pretenden, moi polo contrario, é subverteren a orde estabelecida mediante a transgresión dos patróns de uso da linguaxe para tornaren patentes as asimetrías e os prexuízos subxacentes á orde canónica preestabelecida artellada polo discurso androcéntrico dominante, colocando así as mulleres e o xeito de as representar directamente no centro do debate social:

From this perspective, the object of tampering with linguistic conventions is to make the point that the way of using language which most people consider 'natural' is not natural at all [...] Deliberate departures from conventional usage are meant to bring those assumptions to the surface so they can be noticed, and challenged (Cameron 1995: 156-157). 
A modo de anécdota non tan trivial, é este mesmo reto para cos usos estabelecidos o que provocou un dilatadísimo debate, por non dicir linchamento e ridiculización pública, cando a Ministra de Igualdade, Bibiana Aído, na súa primeira comparecencia no Congreso dos Deputados (sic.) en 2008 usou o termo "miembra" en vez do pseudoxenérico "miembro".

É máis, fronte á posibilidade de romper coa orde estabelecida, na práctica a neutralización pode mesmo agravar a situación, tornando cada vez máis invisíbeis as mulleres e efectivamente varréndoas da lingua. Á súa vez, ao non visibilizar a presenza das mulleres na sociedade a través do idioma, os procedementos de neutralización reforzan por pasiva os estereotipos socioculturais de xénero en canto que as suposicións a respecto do xénero biolóxico dun determinado elemento lingüístico non-marcado responden tanto a connotacións semánticas implícitas condicionadas polo marco sociocultural no que operan como ás denotacións semánticas superficiais (Engelberg 2002: 122; Baxter 2006: 22). Recorrendo ao inglés para exemplificar este caso por ser unha lingua que conta con elementos xenuinamente epicenos, o termo doctor ('médica/o') - a priori nin masculino nin feminino- corre o risco de ser interpretado como masculino de se non marcar explicitamente o contrario debido a que esta profesión se identifica tradicionalmente como masculina. Pola contra, o termo nurse ('enfermeira/o') vai ser interpretado, de non se marcar explicitamente (p.e. male nurse), como feminino, por ser esta unha profesión tradicionalmente identificada como feminina. Obsérvese de paso a asimetría en canto ao prestixio social de cada unha destas dúas profesións e a súa relación coa adscrición implícita de xénero.

Así, as estratexias que pretenden neutralizar a expresión do xénero ‘biolóxico’ na linguaxe corren o risco de seren contraproducentes ao enmascararen prexuízos subxacentes en vez de os poren á descuberta para os poder enfrontar e cuestionar. As estratexias de 'feminización' (Pauwels 1998: 112-116) pretenden, pola contra, actuar da maneira oposta para remediaren esta eiva: "Utilizar les fórmules que fomentin una concepció igualitària del rol de la dona dins la societat: [...] advocada, metgessa, enginyera, arquitecta, governadora, diputada, regidora, consellera, etc." (Institut Balear de la Dona 2001: 10).

Como xa ficou dito, as linguas non coinciden necesariamente no xeito concreto de expresaren nas súas respectivas gramáticas o 'xénero biolóxico'. Sería de esperar, pois, que as estratexias dirixidas a mudaren estes elementos estruturais tamén mudasen en función das características específicas do funcionamento interno destas. É dicir que, por seren estratexias máis acordes cos recursos internos propios en cada caso, sería lóxico pensar que unha lingua como o inglés, que dispón de epicenos, sería máis propensa a aplicar estratexias tendentes á neutralización, mentres que unha lingua romance como o galego, onde a marcaxe morfolóxica é máis clara, optaría máis facilmente por outras vías, como por exemplo a explicitación do xénero, p.e. as/os alumnas/os. 
Dentro do contexto das linguas indoeuropeas pódense distinguir dúas tendencias principais: en primeiro lugar, e ligada principalmente ás linguas xermánicas, está a neutralización mediante a eliminación intencionada de formas explicitamente marcadas como femininas (obsérvese de paso que a neutralización vén da man da eliminación da especificidade feminina) e o uso xeneralizado de formas epicenas ou, no seu defecto, o uso de formas masculinas como pseudoxenéricas": "On the whole, [...] the official Norwegian guidelines follow the strategy of gender-neutralisation rather than genderspecification [...]. Hellinger suggests this strategy is typical of English as well as Norwegian" (Bull / Swan 2002:247). Por exemplo, en inglés: manager/manageress $>$ manager ('director/a') e fireman/-woman(?) > fire fighter ('bombeira/o').

E en segundo lugar, e ligada principalmente ás linguas romances, está a explicitación mediante o uso de formas diferenciadas, p.e. os/as profesores/as ou as profesoras e os profesores. Mais non se trata de compartimentos estanques, senón de tendencias relativas, ao poderen coexistir varias estratexias -quer harmonicamente, quer en competición- dentro dun mesmo sistema, por exemplo estratexias neutralizadoras en galego do tipo o profesorado e radicais/transgresoras que retan as normas estabelecidas do tipo@s profesor@s, ao lado de estratexias explicitantes do tipo os profesores e as profesoras, ou en alemán formas radicais/transgresoras do tipo die LehrerInnen ('@s profesor@s') ao lado de die Leher und die Leherinnen.

A continuación descríbense e analízanse as prácticas e propostas para a planificación non-androcéntrica no galés co obxecto de tentar determinar até que punto a aplicación de determinadas estratexias pode chegar a depender -implícita ou explicitamentedos modelos xa estabelecidos no caso das linguas dominantes respectivas. Ao mesmo tempo procúrase dilucidar se unha maior autonomía non levaría á posibilidade de aplicar estratexias non-androcentrizantes máis acordes cos recursos internos de cada lingua, potencialmente evitando, ou cando menos reducindo, o risco de rexeitamento pretextando a 'anaturalidade' dos resultados.

\section{4. $O$ caso do galés}

A dirección que tomou o desenvolvemento da linguaxe non-discriminatoria no caso da lingua galesa só se pode entender dentro do marco global da lexislación estatal correspondente, nomeadamente a 'Lei sobre a Discriminación Sexual' (Sex

2 A respecto da neutralización, Pauwels (1998: 109) comenta: "This strategy has been proposed for, and applied to, most of the Germanic languages, including English, Danish, Dutch and Norwegian." Non existe, no entanto, unha repartición ríxida das estratexias segundo a familia a que pertence unha determinada lingua. Por exemplo, mentres o inglés e o noruegués optan maioritariamente pola estratexia 'neutralizadora' máis identificada coas linguas xermánicas, o alemán tende, pola contra, cara ás estratexias de 'visualización’ (Bußman / Hellinger 2003: 166). 
Discrimination Act) do Reino Unido de 1975, que abranxe os sectores público e privado, e onde se estabelece o seguinte:

Use of job description with a sexual connotation (such as waiter, salesgirl, postman or stewardess) shall be taken to indicate an intention to discriminate, unless the advertisement contains an indication to the contrary (HMSO 1975: Sección 38/3).

Esta lexislación avoga, pois, pola aplicación dunha estratexia claramente orientada cara á neutralización, partindo, como revelan os exemplos recollidos no enunciado orixinal, das características e usos existentes da lingua inglesa. No entanto, ao ser o País de Gales unha parte integral do Reino Unido, a aplicación da Lei é de obrigado cumprimento tanto alí como na propia Inglaterra, e por extensión aplicábel non só ao inglés, a lingua sobre cuxos recursos internos se elaborou, senón tamén á lingua galesa: "Because this law affects Wales as well as England, it affects job titles in Welsh and English" (Bwrdd yr Iaith Gymraeg s.d.: 1).

A pesar dos problemas específicos internos que presentan as linguas celtas como o galés debido á marcaxe do xénero mediante cambios en certas consoantes iniciais de substantivos e adxectivos concordantes (véxase máis adiante), o que torna(ría) precisa unha dupla marcaxe gramatical para dobretes léxicos ${ }^{3}$, poderíase esperar que o galés seguise o modelo das políticas aplicadas por outras linguas estruturalmente similares como pode ser o galego, fronte ás estratexias de neutralización aplicadas polo inglés grazas á existencia nesta lingua de epicenos formais. No entanto, o que ocorre na realidade contravén esta expectativa baseada nos recursos internos da lingua en cuestión, ao se aplicaren ao galés estratexias neutralizadoras seguindo os principios que rexen a planificación non-discriminatoria tal e como se aplica á lingua dominante correspondente, o inglés: "These guidelines put forward by the Equal Opportunities Commission are therefore formulated largely in terms of a 'neutralisation' strategy" (Awbery / Jones / Morris 2002: 328).

A translación e aplicación mecánicas dun modelo estruturalmente desaxeitado importado directamente das prácticas desenvolvidas especificamente para o inglés trae consigo unha serie de consecuencias negativas, deixando eivada a proposta final para unha linguaxe non-sexista no caso do galés en varios puntos que se pasarán a expor e analizar a seguir.

Por un lado, a política de linguaxe non-discriminatoria para o galés baséase nunha serie de principios básicos, a saber: o uso de "formas idiomáticas naturais no canto

3 Por exemplo: $\underline{\text { cantor }}$ 'cantante (m.)' $+\underline{d} a$ 'bo/boa'> y $\underline{\text { antor }} \underline{\mathrm{d}} a$ 'o cantante bo' vs.: $\underline{\text { cantores }}$ 'cantante (f.)' $+\underline{d} a$ 'bo/boa'> y gantores $\underline{d d} a$, 'a cantante boa'. Esta dupla marcaxe tornaría moi difícil -por non dicir imposíbel- o uso coherente de dobletes do tipo 'o/a profesor/a'. 
de neoloxismos artificiais que non serían facilmente aceptábeis para as/os falantes do galés" (Awbery 2001: 5); o aproveitamento de experiencias anteriores neste campo terminolóxico tal e como se veu desenvolvendo por parte da Comisión para a Igualdade de Oportunidades (Equal Opportunities Commission) e outras entidades, así como "[outras] entidades cívicas (voluntary bodies) que traballan en campos afíns".

Como se verá a continuación, non é froito do azar que o criterio de 'naturalidade' figure destacado en primeiro lugar como punto de partida destas "directrices mestras" ("guiding approach"). É, por suposto, imprescindíbel que as persoas responsábeis da promoción social ('normalización') de linguas minorizadas dentro do marco de comunidades heteroglósicas (bilingüismo desequilibrado en base a unha situación diglósica) procedan coa máxima cautela para aseguraren o maior grao de 'naturalidade' posíbel no campo da terminoloxía e da creación e/ou fixación do léxico, normas de uso, etc., co fin de evitaren alienar a comunidade de falantes, moitas veces presa dunha inseguridade lingüística (Labov 1996, 1972; Bourdieu 1991). De non ser así, calquera intento correría o risco de alentar as dúbidas destas/es falantes a respecto do uso dun código patrón (imposto deste instancias superiores, ou percibido como tal), provocando a utilización preferente da lingua dominante percibida como máis estábel e asentada. Este criterio de 'naturalidade' cobra toda a súa importancia no caso de linguas que, como o gaélico escocés, están a loitar por sobreviviren no limiar mesmo da desaparición, o que motiva talvez -e desmentindo as protestas de MacLeod que encabezan este artigo- a falta de calquera referencia explícita de políticas de intervención lingüística de corte anti-androcéntrico ao longo das 371 páxinas que conforman o Faclair na Pàrlamaid / Dictionary of Terms publicado polo Parlamento de Escocia (McNeir 2001).

Mais tamén cabe recoñecer que as condicións non son idénticas para todas as linguas subordinadas, de forma que, en termos relativos, se pode dicir que, fronte a situacións como a do gaélico escocés, dentro do mesmo marco xeopolítico do Reino Unido, o galés goza dunha situación moito máis favorábel, tanto no nivel dos usos sociais, como tamén no tocante ao apoio político que recibe a súa promoción. Así, non habería que andar con tantísimo coidado para preservar a sempre nebulosa 'naturalidade' lingüística no momento de elaborar políticas de reforma nonandrocéntricas.

É máis, ao existir no caso do galés unha tradición asentada propiamente diglósica dunha variedade literaria da lingua (cymraeg llenyddiol) que convive con variedades locais, reunidas, á súa vez, nun padrón unido tamén artificial (cymraeg llafar), poderíase argumentar que a comunidade de falantes xa está acostumada en certa medida a se enfrontar a formas pouco 'naturais', aceptando habitualmente a existencia de formas que lle son alleas e nalgúns casos moi afastadas da lingua cotiá. O que iso implica na práctica é que, sen desbotar por completo o criterio 
de 'naturalidade' como desiderátum no momento de elaborar propostas e políticas de reforma lingüística non-androcéntrica, ao existir un clima de maior seguridade lingüística -que cabería medir-e maior grao de aceptabilidade preexistente cara ao uso de formas inhabituais, o criterio de 'naturalidade' se podería matizar e minimizar para achegar propostas máis radicais e, se couber, máis acordes non só cos recursos propios da lingua en cuestión senón cos obxectivos últimos da reforma en si. En definitivo, cabería comedir a relativa importancia do criterio de 'naturalidade', descartando mudanzas innecesarias en vez de constituír a priori un criterio sine qua non.

Unha das consecuencias adversas da aplicación prioritaria do criterio de 'naturalidade' consiste, no caso do galés, en lexitimar de entrada o uso de formas dialectais independentemente das desvantaxes que puideren supor para a elaboración dun código non-androcéntrico. O seguinte caso analiza o que ocorre no caso dos termos utilizados en galés para se referir á "muller", elemento básico e pedra de toque de calquera proposta para unha linguaxe non-androcéntrica:

There are quite marked differences in vocabulary as between the Welsh of north and south Wales [...]. Neither the northern form nor the southern form is felt by native speakers to be 'better' in some way than the other; the two forms simply coexist side by side, as regionally determined equivalents. One such instance is the word for 'woman'. In north Wales the normal forms are: dynes (singular) [and] merched (plural). In south Wales the corresponding forms are: menyw (singular) [and] menywod (plural). The EOC [Equal Opportunities Commission] in Wales has already accepted these two sets of forms as equally valid [...]. It was accordingly decided that this same freedom of choice as to regional usage should be incorporated in the standard glossary (Awbery 2001: 9).

Desde o punto de vista puramente filolóxico, o exposto é indiscutíbel. Mais a natureza mesma da calquera planificación lingüística é -pese a quen lle pesar-prescritiva e non descritiva. Non se trata de describir o que ocorre na lingua, senón de ditaminar cales son os usos considerados máis apropiados en determinados casos e segundo determinados parámetros, non só filolóxicos senón tamén socioculturais e -por que non dicilo- ideolóxicos. E, dito sexa de paso, o statu quo non é ideoloxicamente neutro só por ser o modelo dominante. É dicir, a linguaxe non-sexista non se opón á linguaxe 'normal', senón que se contrapón á linguaxe sexista.

Desde o punto de vista dunha análise androcéntrica da linguaxe, porén, as diferenzas entre as diferentes formas dialectais son algo máis problemáticas. O que implica a aplicación práctica desta recomendación que recolle e lexitima o uso das diferentes formas dialectais (por seren 'naturais', enténdase) é un solapamento semántico altamente reprensíbel desde o punto de vista da linguaxe non-androcéntrica entre as orixes etimolóxicas (Pokorny 1959: 739) da forma plural merched ( $<$ merch 
'filla; rapariga') que, no norte do País se usa para se referir ás mulleres adultas, correspondente co singular dynes, á súa vez un derivado de dyn ('persoa, home', sic.).

A recomendación non é problemática de por si dentro dos límites do paradigma propio das falas do norte de Gales, onde alterna a forma plural merched ('mulleres') co singular dialectal correspondente geneth ('rapariga') no canto de *merch. Mais as propostas de planificación lingüística están destinadas, nun principio, a se integraren á lingua común, código separado e autónomo a respecto das diferentes variedades diatópicas. Por tanto, hai que tomar en conta as potenciais consecuencias de determinadas escollas, habida conta da globalidade do código no seu conxunto. Así, o problema radica no feito de que tanto no sur como no norte se utiliza a forma plural merched co sentido de 'fillas', polo que se estabelece unha ligazón de coincidencia formal 'filla' 'muller', sen esquecer o proceso de mudanza semántica do que foi obxecto a forma merched ('raparigas') > merched ('mulleres'), o que reflicte a percepción das mulleres adultas como seres inmaturos que imperaba até non hai tanto tempo dentro da cultura da Europea occidental": "Feminists have commented that this practice in language contributes to a view of women as 'immature' and 'childlike' who do not have to be taken seriously" (Pauwels 1998: 52).

Así, falantes da lingua non suficientemente familiarizadas/os coas peculiaridades dialectais do galés do norte do País poderían entender o uso do termo merched en publicacións oficiais para se referir a mulleres adultas como ofensivo e degradante en sentido estrito ('degradar': reducir o grao ou rango).

Para alén dos inevitábeis puntos de coincidencia, é esencial distinguirmos entre filoloxía/lingüística descritiva por un lado e planificación lingüística prescritiva por outro. Noutras palabras, aínda que as pode -e debe- tomar en conta, o labor fundamental da planificación lingüística non se vertebra ao redor da descrición das variedades existentes, senón na elaboración dun código padrón de uso recomendado que se elabora a partir destas.

En todo o caso, e sempre velando por non alienar innecesariamente a comunidade de falantes, cabe recoñecer que as propostas até agora comentadas afectan sobre todo a linguaxe administrativa, de modo que non se trata xa da lingua coloquial, senón dun uso específico. Así, debería ter a consideración de lingua para fins específicos (véxase Morales Moreno 2008), definida en termos dunha 'sublinguaxe'("sublanguage", Harris 1968: 152; Hirschman / Sager 1982: 28). Noutras palabras: unha variedade lingüística artificial derivada da lingua natural mais ao mesmo tempo diferente dela, co seu

4 Non esquezamos que non foi até 1882 no Reino Unido que as mulleres puideron ser propietarias e dispor libremente dos seus bens sen tutela masculina (Married Women's Property Act) e que só se acadou o voto para todas as mulleres en igualdade de condicións cos homes en 1928 (Representation of the People Act). Na Suíza non se conseguiu o sufraxio universal a escala Federal até 1971 e a escala Cantonal até 1990 ! 
propio código baseado en usos terminolóxicos altamente controlados. En definitiva, a 'anaturalidade' da linguaxe administrativa a respecto da lingua común é, de entrada, un dos seus trazos definitorios, entrando, pois, en contradición coa 'naturalidade' antes enunciada como criterio de predilección na elaboración de terminoloxía antiandrocéntrica cando menos no campo dos usos administrativos.

Neste caso en concreto, existe a posibilidade de promover o paradigma propio das falas do sur (menyw od) ao rango de modelo a seguir na linguaxe administrativa, de forma que pasa a se converter na forma supradialectal recomendada por ser máis equitativo nas representacións simbólicas que proxecta da muller fronte ao home, sendo esta escolla avalada, para alén de máis, pola propia orixe do termo (Pokorny 1959: 473).

De feito, fronte á disxuntiva de ter que escoller unha ou outra forma, a Comisión para a Igualade de Oportunidades opta na práctica pola forma menyw od, como, por exemplo, no título da publicación Menywod. Dynion. Gwahanol. Cydradd ('Mulleres. Homes. Diferentes. Iguais', Awbery, 2001), en consonancia coa apelación galesa Cymorth i Fenywod yng Nghymru da organización 'Axuda para as Mulleres de Gales', citada especificamente como unha das organizacións de referencia para a elaboración de terminoloxía neste campo (Awbery 2001: 6).

En aras á coherencia, a unha política que referenda a forma discutíbel merched pretextando o seu enraizamento dialectal non lle cabería máis alternativa do que incluír os restantes elementos do mesmo paradigma. E se o uso de merched como forma plural é discutíbel, éo aínda máis a forma singular correspondente dynes, que non é máis, como xa se sinalou, que un hipónimo derivado morfoloxicamente do hiperónimo de $d y n$ ('home') que marca simbólica e efectivamente a muller como unha especie de subtipo de ser humano, entendido este como varón por antonomasia 5 .

No entanto, pese a reiterados chamamentos en defensa da escolla preferente de formas 'naturais', trátase dun criterio que nin sempre se respecta na práctica por motivos moito menos louvábeis -ao noso ver- que a paridade de xénero, como ilustra o seguinte exemplo:

positive action > gweithredu positif: Both 'positif' and 'cadarnhaol' are found in the sources, and are acceptable. The choice of 'positif' here is essentially arbitrary, and if this were preferred, it could be replaced by 'cadarnhaol' (Awbery 2001: 34).

É máis, non se explica por que a comunidade de falantes supostamente rexeitaría neoloxismos anti-androcéntricos por seren imposicións vindas do inglés (Awbery /

5 É interesante destacar que a par da desviación semántica que transforma mulleres en nenas, ao mesmo tempo a palabra que orixinariamente significa 'persoa' (Pokorny 1959: 415, 260) pasa a significar 'home, varón'. 
Jones / Morris 2002: 328), mentres que, por outro lado, se manteñen outras formas clarisimamente anglizadas, p.e. sterioteipio ('estereotipo') por seren máis 'naturais'. Cabería preguntarse, pois, se non é, talvez, que o que no fondo se está realmente a rexeitar non é nin máis nin menos que a necesidade mesma de reformar a lingua para que non for sexista.

Xa se indicou que existe a posibilidade de recorrer a substantivos colectivos para evitar a explicitación do xénero como parte dunha estratexia de 'neutralización'. Esta plásmase na práctica de dúas maneiras radicalmente opostas: "Terms should be used that are non-gender specific, e.g. i. Plural terms: athrawon, gwieithwyr profiadol; ii. Non-specific terms: swydd weinyddiol, staff bar, swyddog ymchwil" (Bwrdd yr Iaith Gymraeg s.d.: 3).

Por un lado, cómpre recalcar que os substantivos colectivos (p.e. 'alumnado') non expresan exactamente o mesmo valor semántico que o conxunto dos individuos que forman parte deles (p.e. 'alumnas e/ou alumnos') e o seu uso indiscriminado, motivado moitas veces por razóns puramente estéticas en vez de entender as verdadeiras razóns, leva a expresións pouco correctas desde o punto de vista da realidade que tentan expresar. Bo exemplo disto témolo en galego na expresión 'pais e nais do alumnado', que non ten, nin moito menos, o mesmo valor que o máis correcto 'pais e nais das alumnas e dos alumnos', ao existir un vínculo individual entre cada nai/pai e as súas respectivas fillas e/ou fillos, diferente dos dereitos que se corresponden ás alumnas e alumnos no seu conxunto como tal colectivo, en contraposición, por exemplo, ao colectivo do profesorado. Non son sempre compatíbeis unha estética non-sexista coa concisión e elegancia lingüísticas, e, por tanto, cabería preguntarse en tales casos cal é o elemento que debe prevalecer: a paridade de xénero ou a 'naturalidade' gramatical.

Porén, o que máis chama a atención no caso citado é o uso recomendado de pseudoxenéricos masculinos (athrawon 'profesores', sic.), o que non representa unha neutralización da marcaxe de xénero estrito senso, senón que esconde unha supeditación do xénero feminino ao masculino, ao existir un feminino plural regular athrawesau (< athrawes), ao lado da forma masculina athrawon $(<\text { athro })^{6}$.

Máis unha vez, esta decisión responde á aplicación do criterio de 'naturalidade' apoiada nos usos maioritarios da lingua no seu estado actual, onde o plural propio do feminino non está estendido. Agora ben, se as políticas de planificación lingüística pretenden preservar formas xenuínas da lingua xeral fronte a formas anglizadas, non se entende por que non se podería recuperar intencionadamente, aínda que só for no nivel da linguaxe administrativa, outras formas tamén xenuínas cun claro

6 Esta flexión segue a formar parte dos recursos gramaticais da lingua moderna, como indica King (1993: 53): "Feminine nouns in -es denoting persons, derived from male equivalent. Examples: [...] (athro) athrawes athrawesau 'teacher/teachers' (f)". 
fin ideolóxico, nomeadamente a representación de mulleres e homes en igualdade de condicións. Sexa como for, non se entende a aplicación de pseudoxenéricos masculinos para se referir tanto a homes como a mulleres como unha estratexia compatíbel cunha auténtica política de neutralización.

O que se esconde talvez detrás desta proposta é o afán de mimetismo a respecto dos procedementos xa aplicados no caso do inglés, mais que demostran ser totalmente inapropiados para o galés debido ás diferenzas nas súas respectivas expresións gramaticais do xénero, ao existir en inglés, cando menos no nivel denotativo formal, epicenos reais (p.e. 'teacher $\sim$ teachers') inexistentes no galés. A seguinte declaración de principios é ilustrativa de até que punto se pode chegar a tentar forzar unha lingua a cumprir cunha política desenvolvida por e para outra estruturalmente diferente: "One term should be used where possible [...]. Although nouns ending in $-y d d$ are masculine with a possible feminine $-y d d e s)$, in practice they are treated as neuter (Bwrdd yr Iaith Gymraeg s.d.: 3).

É dicir que, que se recoñece tacitamente que os substantivos deste tipo en galés están marcados morfoloxicamente para expresaren o xénero natural dos seus referentes reais, mais, para se conformar á estratexia neutralizadora desenvolvida para o inglés partindo do uso de epicenos, créanse pseudoxenéricos ad hoc a partir das formas masculinas. Esta aplicación mimética do modelo importando desde a lingua dominante suscita dúas cuestións importantes: por un lado, desde o punto de vista propiamente lingüístico, cabería preguntarse se iso non constitúe de por si unha vulneración do principio predominante de 'naturalidade'; e por outra, desde o punto de vista ideolóxico, se realmente cómpre cunha linguaxe non-sexista a androzinixazión global da mesma para eliminar as diferenzas de xénero.

Para evitar tales tautoloxías que na realidade non fan máis do que agravaren o nesgo androcentrismo preexistente en vez de o paliaren, cabería rachar coa relación de dependencia do galés do modelo inglés na procura de alterativas máis apropiadas e acordes cos recursos lingüísticos internos propios de cada lingua.

En definitivo, a elaboración dunha linguaxe non-androcéntrica en galés está eivada en dous niveis diferentes: no nivel interno, cabería relativizar o criterio de 'naturalidade' como factor determinante na escolla de determinadas formas lexicais, sobre todo no ámbito da linguaxe administrativa; e no nivel externo, debido á falta de coincidencia no xeito de plasmar o xénero 'biolóxico' a través das súas respectivas gramáticas, a falta de autonomía na planificación do galés con fins anti-androcéntricos a respecto do peso preponderante do modelo preestablecido correspondente ao inglés leva a unha dependencia orientada cara á adopción de propostas pouco axeitas para os recursos propios do galés. Nalgúns casos, a translación mecánica de solucións desaxeitadas peora en vez de mellorar o nesgo preexistente, como o uso recomendado de pseudoxénericos masculinos, motivado pola existencia de epicenos reais en inglés. 


\section{Conclusións}

A análise das estratexias aplicadas no caso do galés co fin de acadar unha linguaxe non-sexista e as súas implicacións permite tirar as seguintes conclusións, válidas en moitos casos non só para a lingua galesa, senón que extensíbeis tamén a outras lingua sen situacións de dependencia similares. A aplicación do criterio de 'naturalidade' lingüística na elaboración de propostas concretas para evitar a alienación da comunidade de falantes, moitas veces vítimas dunha inseguridade lingüística imperante derivada da situación desigual da lingua subordinada a respecto da lingua dominante, non pode ser un criterio de selección de partida, senón que cómpre relativizar o seu valor dependendo dos efectos que se pretendan acadar. Sobre todo no caso dos usos formais da lingua dentro dun marco administrativo, entendida como unha linguaxe para fins específicos, este criterio perde, obxectivamente, grande parte do peso por ser esta unha linguaxe 'naturalmente anatural'.

Non debemos esquecer que o que se considera ou se deixa de considerar 'natural' depende, sobre todo, de quen o definir: é unha cuestión ideolóxica. Pensando xa no caso do galego, se o castrapo é cada vez máis 'natural', implicaría iso termos que renunciar a recuperar voces auténticas? Para retomarmos o título dun recente ensaio: "O natural é político" (Moure 2008).

Canto, por outra parte, ás estratexias adoptadas, indícase a posibilidade de combinar estratexias tendentes á neutralización da expresión do xénero 'natural/biolóxico' nos usos lingüísticos con outras estratexias tendentes á súa explicitación. Non se exclúen tampouco estratexias máis radicais cuxo obxectivo consiste máis en desenmascararen e en cuestionaren os usos estabelecidos do que en reformaren a linguaxe de xeito sutil e imperceptíbel. En todo o caso, destácase o risco de invisibilizar as mulleres que pode supor a adopción de estratexias neutralizadoras, sobre todo aquelas que pretenden estender o uso de pseudoxenéricos masculinos que, lonxe de reequilibraren o nesgo sexista existente dos usos lingüísticos estabelecidos, obxectivamente non fan máis do que tornaren a lingua aínda máis androcéntrica.

Esta opinión é radicalmente contraria aos postulados que serven de base para a elaboración das propostas de planificación non-sexista no caso do galés:

The alternative 'visibility' strategy, which would involve creating forms to give male/female pairs was avoided [...] as it was felt that the Welsh-speaking community would regard the introduction of new, nonstandard lexical forms as linguistic imperialism on the part of the English-speaking officials, with no understanding of or sympathy with the Welsh language (Awbery / Jones / Morris 2002: 328).

Por último, o artigo analizou os potenciais riscos implícitos no mimetismo por parte das linguas subordinadas, partindo da translación e aplicación mecánica de políticas 
elaboradas con anterioridade para a lingua dominante correspondente, sobre todo ao existiren diferenzas importantes no xeito de se plasmar o xénero 'biolóxico' das/os referentes humanas/os nas súas respectivas gramáticas.

En definitiva, independentemente da(s) estratexia(s) privilexiada(s) en cada caso, ao noso ver, a planificación lingüística que pretende elaborar un código de uso nonandrocéntrico non é necesariamente incompatíbel coa planificación lingüística xeral na súa vertente tradicional que ten como fin a conservación e promoción dunha lingua subordinada/ameazada.

Como ben indica Echeverria (2003), é un paradoxo que a mesma supremacía que vén exercendo a lingua dominante sobre a lingua subordinada se poida chegar a transformar nunha dominación dunha parte das falantes desta (as mulleres) a través das tentativas de conservación e promoción, pretextando a necesidade de preservar as formas e usos tradicionais da lingua subordinada, percibida como o vehículo de valores tradicionais, sen entrar a avaliar se é realmente tan desexábel preservar todos estes valores no seu conxunto, incluído o androcentrismo que predomina na sociedade tradicional.

No fondo, a cuestión non é tanto como se pode facer para preservar a lingua nunha especie de 'estado puro', correndo o conseguinte risco da musealización, senón como facer para que a lingua sexa unha ferramenta plenamente adaptada ás novas necesidades comunicativas e sociais do século XXI. En definitivo, se cómpre mudar a lingua ao introducir elementos terminolóxicos novos para falar, poñamos por caso, das novas tecnoloxías, por que razón non se debería poder facer o mesmo para incorporar novos valores sociais, entre os cales destaca (ou debería destacar) a consideración de paridade entre os xéneros. E de o non facer -en aras a non alienar os falantes nativos ( $\mathrm{sic}$.) - ao mellor o que se consegue, polo contrario, é alienar unha parte importante da comunidade de falantes reais e potenciais: as mulleres.

\section{Bibliografía:}

Awbery, G. (2001): Women. Men. Different. Equal. A Standard Glossary of Welsh Terms in the Field of Equal Opportunity. Report to the Equal Opportunities Commission in Wales. / Menywod. Dynion. Gwahanol. Cydradd. Rhestr o Dermau Safonol Cymraeg ym maes Cyfle Cyfartal. Adroddiad I'r Comisiwn Cyfle Cyfartal yng Nghymru (Cardiff/Caerdydd: Equal Opportunities Commission / Comisiwn Cyfle Cyfartal).

Awbery, G. / Jones, K. / Morris, D. (2002): "The politics of language and gender in Wales'", en Bußman, H. / Hellinger, M. (eds.), Gender across language. Vol. 2: 313-330 (Amsterdam / Philadelphia: John Benjamins). 
Baxter, R. N. (2006): "Falocentrismo e heteronormatividade na tradución: de como varren as mulleres e as lesbianas da historia cun golpe de pence", Revista Galega de Filoloxía, 7: 11-28.

Bußman, H. / Hellinger, M. (2003): "Engendering female visibility in German”, en Bußman, H. / Hellinger, M. (eds.), Gender across language. Vol. 3: 141-174 (Amsterdam / Philadelphia: John Benjamins).

Bull, T. / Swan, T. (2002): “The representation of gender in Norwegian”, en Bußman, H. / Hellinger, M. (eds.), Gender across language. Vol. 2: 219-249 (Amsterdam / Philadelphia: John Benjamins).

Bourdieu, P. (1991): Language and Symbolic Power (Cambridge, EUA: Harvard University Press).

Bußman, H. / Hellinger, M. (eds.) (2001-2003), Gender across language. 3 vols. (Amsterdam / Philadelphia: John Benjamins).

Bwrdd yr Iaith Gymraeg (s.d.): Teitlau Swyddi Dwyieithog / Bilingual Job Titles (Caerdydd / Cardiff: Bwrdd yr Iaith Gymraeg / The Welsh Language Board).

Cameron, D. (1995): Verbal Hygiene (Londres / Nova Iorque: Routledge).

Cameron, D. (1998): "Lost in Translation: Non-sexist Language", en Cameron, D. (ed.), The Feminist Critique of Language: 155-163 (Londres / Nova Iorque: Routledge).

Corbett, G. (1991): Gender (Cambridge: Cambridge University Press).

HMSO (1975): Sex Discrimination Act (Londres: The Stationery Office) <http://www. legislation.hmso.gov.uk/si/si2003/20031657.htm>

Doyle, M. (1995): The A-Z of Non-Sexist Language (Londres: The Women's Press).

Echeverria, B. (2003): "Language Ideologies And Practices In (En)Gendering The Basque Nation", Language In Society, 32: 383-413 (Cambridge: Cambridge University Press).

Engelberg, M. (2001): “The Communication of Gender in Finnish”, en Bußman, H. / Hellinger, M. (eds.), Gender across language. Vol. 2 (Amsterdam / Philadelphia: John Benjamins).

Harris, Z. (1968): "Mathematical structures of language", (Nova Iorque: Interscience Publishers).

Hirschman, L. / Sager, N. (1982): "Automatic information formatting of a medical sublanguage', en Kittredge, R. / Lehrberger, J. (eds.), Sublanguage; studies of language in restricted semantic domains: 27-80 (Berlín / Nova Iorque: W. de Gruyter).

Institut Balear de la Dona (2001): Llenguatge no sexista. La comunicació: un recurs per a la igualtat (Palma de Mallorca: Govern de les Illes Balears). 
King, G. (1993): Modern Welsh: A Comprehensive Grammar (Londres / Nova Iorque: Routledge).

Labov, W. (1966): "Hypercorrection by the lower middle class as a factor in linguistic change”, en Bright, W. (ed.), Sociolinguistics: 84-113 (A Haia: Mouton).

Labov, W. (1972): Sociolinguistic Patterns (Philadelphia: University of Pennsylvania Press).

MacLeod, M. (2003): "Ochone! The curse of political correctness hits Gaelic language", (ed.), Scotland on Sunday (13.07.03) <http://scotlandonsunday.scotsman.com/ scotland.cfm?id $=762452003>$

McNeir, C. L. (ed.): Faclair na Pàrlamaid / Dictionary of Terms (Dùn Èideann / Edimburgo: Pàrlamaid na h-Alba / The Scottish Parliament).

Morales Moreno, A. (2008): “Aspectes estilístics en la redacció de textos administratius: anàlisi comparativa dels estatuts d'Autonomia de Catalunya de 1979 i de 2006", Revista de llengua i dret, 49: 27-44.

Moreno, M. (2008): El sueño de Eva (Sevilla: rd editores).

Moure, T. (2008): O natural é politico (Vigo: Xerais).

Oroz, A. (s.d.): “Sexo, genética y género”, Soca, R. (resp.) (10.06.04), La página del idioma español (elcastellano.org) <http://www.elcastellano.org/nosex.html >

Pauwels, A. (1998): Women Changing Language (Londres / Nova Iorque: Longman).

Pokorny, J. (1959): Indogermanisches Etymologisches Wörterbuch (Berlín e Munich: Francke Verlag).

Rodríguez Rodríguez, A. / Davila Ventura, M. (redac.) (2003): Lingua galega. Criterios lingüísticos (Vigo: Universidade de Vigo).

Romaine, S. (1999): Communicating Gender (Mahwah / Londres: Lawrence Erlbaum).

Spender, D. (1980): Man made Language (Londres: Pandora Press). 